Molecules 2001, 6, 881-891

\title{
molecules
}

ISSN 1420-3049

http://www.mdpi.org

\section{Syntheses of (Diacetoxyiodo)arenes or Iodylarenes from Iodoarenes, with Sodium Periodate as the Oxidant ${ }^{\dagger}$}

\section{Pawel Kazmierczak, Lech Skulski* and Lukasz Kraszkiewicz}

Chair and Laboratory of Organic Chemistry, Faculty of Pharmacy, Medical University, Banacha 1, PL 02-097 Warsaw, Poland

$\dagger$ This paper was presented at the Fifth Electronic Conference on Synthetic Organic Chemistry (ECSOC-5), September 1-30, 2001 (Paper A0005).

* Author to whom correspondence should be addressed; Tel/Fax: +48(22)8226843; e-mail: 1skulski@,farm.amwaw.edu.pl

Received: 27 September 2001; in revised form 11 October 2001 / Accepted: 12 October 2001 / Published: 31 October 2001

\begin{abstract}
Easy, safe, and effective novel methods for preparing either (diacetoxyiodo)arenes, $\mathrm{ArI}(\mathrm{OAc})_{2}$, or iodylarenes, $\mathrm{ArIO}_{2}$, from the corresponding iodoarenes, ArI, using sodium periodate as the oxidant are presented in this paper. In order to obtain 2- and 4iodylbenzoic acids, the respective sodium salts of 2- and 4-iodobenzoic acids should be used as the starting substrates, because mixtures containing the corresponding iodosyl derivatives as the main products along with the intended iodyl compounds are produced from the free parent acids.
\end{abstract}

Keywords: (Diacetoxyiodo)arenes, iodylarenes, iodoarenes, sodium periodate as oxidant 


\section{Introduction}

(Diacetoxyiodo)arenes, $\operatorname{ArI}(\mathrm{OAc})_{2}$, and in particular the parent compound (diacetoxyiodo)benzene, $\mathrm{PhI}(\mathrm{OAc})_{2}$, have been known for a long time [1-5]. They are potent, often chemoselective, oxidizing agents. They are also used for the facile syntheses of, for example, [bis(trifluoroacetoxy)iodo]arenes or [hydroxy(tosyloxy)iodo]arenes (as selective oxidants), and aromatic iodonium salts (as arylating reagents) [2-6]. There are several preparative methods for these compounds. So far, the substrates used have generally been [2-5]: (i) iodosylarenes dissolved in glacial acetic acid; (ii) (dichloroiodo)arenes in which chloride is exchanged by acetoxy groups coming either from silver, lead(II) or sodium acetate, or from acetic acid in the presence of mercury(II) oxide in chlorinated solvents; (iii) iodoarenes which are oxidized in warm glacial acetic acid by either peracetic acid [5], sodium perborate [7], or chromium(VI) oxide (this last work accomplished in our laboratory) [8], or electrolytically $[3,4]$. The standard, and most general, method for the synthesis of $\operatorname{ArI}(\mathrm{OAc})_{2}$ (the oxidative diacetoxylation of iodoarenes by warm peracetic acid solution) is, in fact, a very prolonged reaction (12-16 h), and the utmost care should be taken to exactly maintain the temperature required $\left(40^{\circ} \mathrm{C}\right)[5]$. The $\operatorname{ArI}(\mathrm{OAc})_{2}$ are generally crystalline compounds, fairly stable in the air, which may be stored for long periods by avoiding light; the same is true in respect to the iodylarenes, $\mathrm{ArIO}_{2}$, which are discussed below, but it should be noted that the melting points of many $\mathrm{ArIO}_{2}$ are, in fact, their decomposition points, often accompanied by explosion (see Table 2).

The first organic compound of iodine (V), iodylbenzene, $\mathrm{PhIO}_{2}$, was prepared by Willgerodt 101 years ago [1]. Since then various iodylarenes, $\mathrm{ArIO}_{2}$, have been reported [1, 3-5]. For a long time rather very few $\mathrm{ArIO}_{2}$ have been used as useful oxidants in organic synthesis. Their former limited applications were mostly due to their polymeric nature, which makes them insoluble in most ordinary solvents, except water. Moreover, they should always be handled with care, since violent decomposition of several $\mathrm{ArIO}_{2}$ can been induced e.g. by scraping them with a spatula, on heating above $200^{\circ} \mathrm{C}$, and also upon impact. However, since ca. 1980 a quickly growing importance in modern organic synthesis of $\mathrm{PhIO}_{2}$, 3-iodylbenzoic acid, 4-(t-butyl)iodylbenzene, "2-iodylbenzoic acid" [which, in fact, has a cyclic structure, i.e. 1-hydroxy-1,2-benziodoxol-3(1H)-one 1-oxide], and particularly its more safe triacetoxy derivative, named the Dess-Martin reagent [1,1,1-triacetoxy-1,2benziodoxol-3(1H)-one] has been reported in numerous papers [3-6, 9]. They are commonly used as moderate and very selective oxidants. $\mathrm{ArIO}_{2}$ are also useful in the preparation of diaryliodonium salts. In the last short review [9] the opinion has been put forward that "2-iodylbenzoic acid" and the corresponding Dess-Martin reagent may, most satisfactorily, be prepared as illustrated in Scheme 1.

Sharefkin and Saltzman [10] and more recently Indian chemists [11] have briefly reviewed all the previously reported oxidative methods for preparing $\mathrm{ArIO}_{2}$ from either the corresponding $\mathrm{ArI}, \mathrm{ArICl}_{2}$, or ArIO. In their review [11] the latter authors provided the following critical assessment: "The reported methods of Lucas and Kennedy [12] (i.e. by the thermal disproportionation of ArIO to $\mathrm{ArIO}_{2}$ and ArI) for the preparation of $\mathrm{PhIO}_{2}$ from PhIO proved to be lenghty and irksome in our hands while that of Sharefkin and Saltzman [10] was neither economical nor free of danger for the use of commercial $40 \%$ peracetic acid, though the yield of the desired $\mathrm{PhIO}_{2}$ (obtained there from $\mathrm{PhI}$ ) in this single step reaction was excellent" (72-82\%). 


\section{Scheme 1}

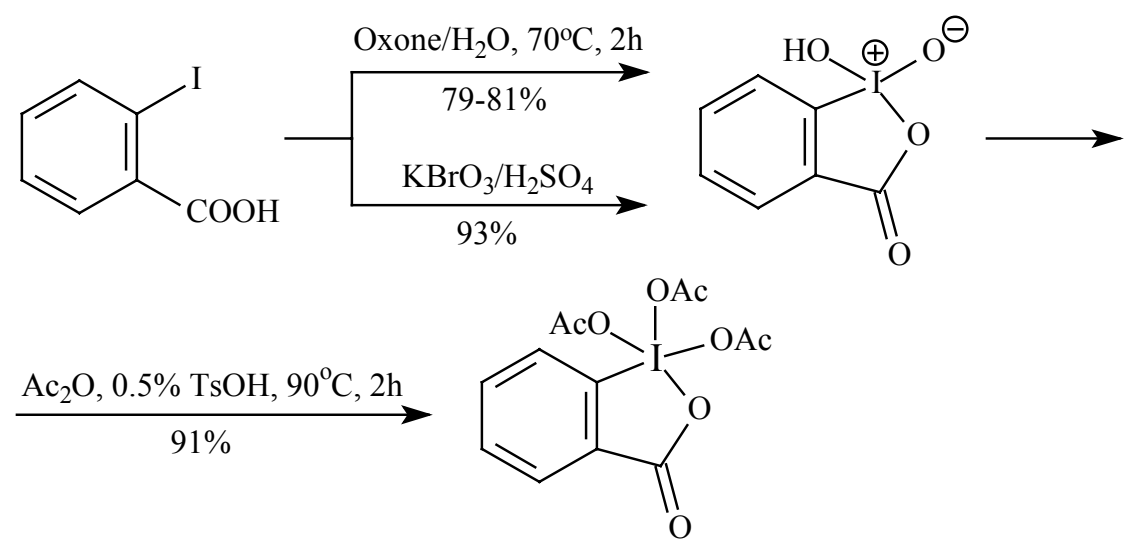

The Indian chemists [11] oxidized several ArI using $\mathrm{KBrO}_{3}$ under strongly acidic conditions, which afforded the respective $\mathrm{ArIO}_{2}$ in 46-96\% yields. In 1993, a two-phase method was reported [13], involving the direct oxidation of ArI using aqueous hypochlorite and a phase transfer catalyst, $\mathrm{Bu}_{4} \mathrm{~N}^{+} \mathrm{HSO}_{4}^{-}$. Italian chemists [14] instead used Oxone ${ }^{\circledR}$ to oxidize 2-iodobenzoic acid to "2-iodylbenzoic acid", and they criticized the "classic" $\mathrm{KBrO}_{3} / \mathrm{H}_{2} \mathrm{SO}_{4}$ procedure [11] as follows: "The $\mathrm{KBrO}_{3}$ based oxidation methods are unappealing for the user in that the reaction is performed in hot aqueous $\mathrm{H}_{2} \mathrm{SO}_{4}(0.73 \mathrm{M}), \mathrm{KBrO}_{3}$ is classified as a carcinogen $(\mathrm{R}-45)$ in the international classification of substance toxicity, and obnoxious bromine vapors are copiously evolved (62 $\mathrm{g} / \mathrm{mol}$ of "2-iodylbenzoic acid") from the reaction mixture, with personal and environmental contamination risk. Still, incomplete oxidation of 2-iodobenzoic acid is not totally avoided and recovered "2-iodylbenzoic acid" is contaminated with variable amounts of less-oxidized precursors". They prepared several batches of "2-iodylbenzoic acid" using the "classic" Indian method [11]. The purity of this reagent varied between 90 and 95\%, the major contaminants being 2-iodobenzoic acid (1-3\%) and "2-iodosylbenzoic acid" (5-10\%). It was also suggested that the explosive properties of some samples of "2-iodylbenzoic acid" were due to the presence of bromate or other impurities.

\section{Results and Discussion}

Previously, we have devised in our laboratory [8] a simple, two-step conversion of various ArI to $\mathrm{ArI}(\mathrm{OAc})_{2}$ in the anhydrous $\mathrm{CrO}_{3} / \mathrm{AcOH} / \mathrm{Ac}_{2} \mathrm{O} /$ conc. $\mathrm{H}_{2} \mathrm{SO}_{4}$ liquid system, followed by mixing with excess $20 \%$ aqueous ammonium acetate solution which afforded, after purification, $\operatorname{ArI}(\mathrm{OAc})_{2}$ in 58 $82 \%$ yields. $\mathrm{PhI}(\mathrm{OAc})_{2}$, for example, was prepared from $\mathrm{PhI}$ in $79 \%$ yield. This procedure is $8-16$ times faster and ca. 5 times less expensive than the method of McKillop and Kemp [7]. However, this method is hardly applicable for iodotoluenes [4- $\mathrm{MeC}_{6} \mathrm{H}_{4} \mathrm{I}(\mathrm{OAc})_{2}$ was obtained from 4- $\mathrm{MeC}_{6} \mathrm{H}_{4} \mathrm{I}$ in only $20 \%$ yield], while iodoanisoles were quickly oxidized in the reaction mixtures, with the evolution of iodine vapors, and the formation of tarry products. In our present work we have developed a quick and efficient oxidative method, which allows us to obtain also the respective pure $\operatorname{ArI}(\mathrm{OAc})_{2}$ from $\operatorname{ArI}$ substituted with the methyl or methoxy group (Table 1) - hence this complements nicely our former procedure [8]. The essence of our novel method is described in Scheme 2. 


\section{Scheme 2}
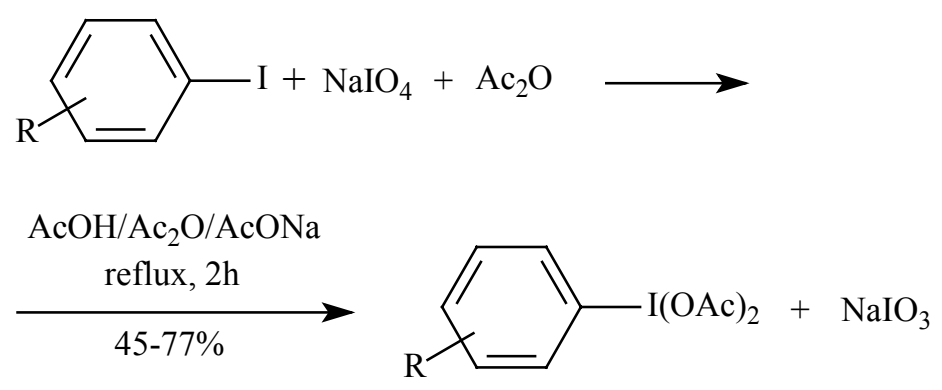

$\mathrm{R}=\mathrm{H}, 4-\mathrm{F}, 4-\mathrm{Br}, \mathrm{Cl}$ (three isomers), $\mathrm{Me}$ (three isomers), $\mathrm{OMe}$ (three isomers).

The above oxidative reactions were carried out in boiling, anhydrous binary $\mathrm{AcOH} / \mathrm{Ac}_{2} \mathrm{O}$ mixtures. The presence of sodium acetate (in stoichiometric quantities) in the reaction mixtures was indispensable - without its addition the oxidation reactions did not proceed; when sodium acetate was replaced by pyridine, then the final yields of $\operatorname{ArI}(\mathrm{OAc})_{2}$ were lowered by ca. $10-20 \%$. After completing the oxidative reactions, the reaction mixtures were poured into water, the collected solids were washed and air-dried in the dark, and were recrystallized from ethyl acetate admixtured with acetic anhydride to reacetylate the partly hydrolyzed crude products (cf. Ref. [8]). After cooling, excess hexane was added to improve the crystallization yields (Table 1). The parent pure $\mathrm{PhI}(\mathrm{OAc})_{2}$ was obtained from $\mathrm{PhI}$ in $73 \%$ yield, the other yields are given in Table 1. This method is not applicable for ArI substituted with strong electron-withdrawing groups. The purities of the purified products, $\operatorname{ArI}(\mathrm{OAc})_{2}$, were checked by mixed melting points with authentic specimens as well as with ${ }^{1} \mathrm{H}-\mathrm{NMR}$ spectra and elemental analyses. For more details see Experimental and Table 1.

The heterophasic reactions of various iodoarenes (Table 2) suspended in vigorously stirred boiling aqueous sodium periodate solutions proceeded smoothly within 8-16 hours to give the corresponding colorless iodylarenes in 58-91\% crude yields (Scheme 3):

\section{Scheme 3}
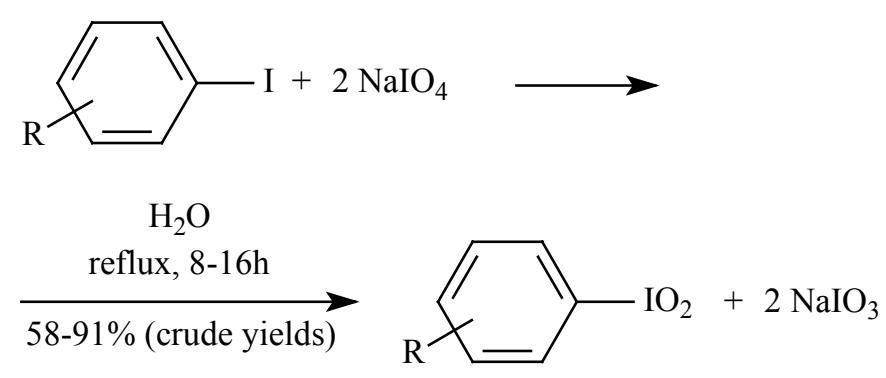

$\mathrm{R}=\mathrm{H}, 4-\mathrm{OMe}, \mathrm{Me}$ (three isomers), 4-F, 3- and 4-Cl, 4- $\mathrm{Br}$, 3- and 4- $\mathrm{NO}_{2}, 3-\mathrm{COOH}$, 2- and 4-COONa (see below for explanation). 
When the above reactions were completed, the reaction mixtures were diluted with ice water. The collected precipitates were washed on the filter with cold water, followed by $\mathrm{CHCl}_{3}$ or acetone (to remove the unreacted ArI), and then air-dried in the dark. Iodometric titrations [15] showed that our crude $\mathrm{ArIO}_{2}$ had 98-99\% purity, hence they may be used directly in various subsequent reactions. These crude products did not oxidize KI in a saturated sodium borate solution (a reaction which differentiates iodosyl compounds from iodyl compounds [15]). Small samples of the crude products were recrystallized from boiling water to give the analytical specimens, whose melting/detonation points were close to those reported in the literature (Table 2). Their IR solid spectra displayed the characteristic frequencies for $\mathrm{ArIO}_{2}$, in the spectral region $710-800 \mathrm{~cm}^{-1}[3,11]$.

The reaction mixtures discussed above were nearly neutral. When they were made alkaline by the addition of an aqueous $\mathrm{NaOH}$, the unreactive $\mathrm{Na}_{3} \mathrm{H}_{2} \mathrm{IO}_{6}$ precipitated out, and the reactions did not proceed. Negative results were also obtained, when $\mathrm{NaIO}_{4}$ was replaced for $\mathrm{NaIO}_{3}$ as the oxidant under the same reaction conditions. 3-Iodobenzoic acid gave 3-iodylbenzoic acid without problem in boiling aqueous $\mathrm{NaIO}_{4}$ solution (Table 2). But 2- and 4-iodobenzoic acids gave mainly either cyclic "2-iodosylbenzoic acid" [i.e. 1-hydroxy-1,2-benziodoxol-3(1H)-one] in 76\% crude yield, or 4iodosylbenzoic acid in ca. $84 \%$ crude yield. Iodometric titrations [15] showed that the crude cyclic "2iodosylbenzoic acid" was only slightly admixtured with the iodyl derivative (ca. 5\%), while the crude 4-iodosylbenzoic acid contained ca. 40-50\% of the corresponding iodyl derivative. However, when the sodium salts of the two acids (prepared in situ, see Experimental) were reacted as above with boiling aqueous $\mathrm{NaIO}_{4}$ solutions, then this resulted in the formation of either the cyclic "2-iodylbenzoic acid" (vide supra) in $71 \%$ crude yield, or 4-iodylbenzoic acid in $88 \%$ crude yield. Iodometric titrations [15] showed that they were $98-99 \%$ pure. After recrystallizations from boiling water, their chemical structures were supported analytically, spectrally (IR), and by their characteristic melting/detonation points. In our opinion, these two crude products may also be used directly in many subsequent reactions, because they have a satisfactory purity.

The proposed multistage mechanism of converting iodoarenes to iodylarenes, with using $\mathrm{NaIO}_{4}$ as the oxidant in boiling water, would be as follows:

\section{Scheme 4}

$$
\begin{aligned}
& 2 \mathrm{ArI}+2 \mathrm{NaIO}_{4} \text { (in boiling water) } \longrightarrow 2 \mathrm{ArIO}+2 \mathrm{NaIO}_{3} \\
& 2 \mathrm{ArIO} \text { (in boiling water }) \longrightarrow \mathrm{ArIO}_{2} \text { (stable product) }+\mathrm{ArI} \text {, etc. }
\end{aligned}
$$

$$
. \mathrm{ArI}+2 \mathrm{NaIO}_{4} \longrightarrow \mathrm{ArIO}_{2}+2 \mathrm{NaIO}_{3}
$$

In the course of the above reactions (Scheme 3), at first some yellowish colored solids were observed to copiously precipitate out (their color being characteristic of ArIO), which were then gradually transformed into the final colorless products, $\mathrm{ArIO}_{2}$. It is known [1, 3-5] that thermally unstable ArIO cannot be recrystallized from hot or boiling water, in contrast to $\mathrm{ArIO}_{2}$, since they 
readily disproportionate as follows [1, 12]: $2 \mathrm{ArIO} \rightarrow \mathrm{ArIO}_{2}+\mathrm{ArI}$. However, when 2-iodobenzoic acid was oxidized with $\mathrm{NaIO}_{4}$ in boiling water, then the formed 2-O $\mathrm{OCC}_{6} \mathrm{H}_{4} \mathrm{COOH}$ would momentarily transform into its cyclic (and fairly thermostable) desmotropic form, 1-hydroxy-1,2-benziodoxol$3(1 H)$-one, and its subsequent thermal disproportionation was hardly possible; this was not the case when sodium 2-iodobenzoate (and sodium 4-iodobenzoate) was oxidized with $\mathrm{NaIO}_{4}$ in boiling water (see Experimental). From the above it is seen that $\mathrm{NaIO}_{4}$ used as the oxidant either in boiling $\mathrm{AcOH} / \mathrm{Ac}_{2} \mathrm{O} / \mathrm{AcONa}$ solutions (Scheme 2) or in boiling water (Schemes 3 and 4) does, in fact, oxidize the iodine atoms in iodoarenes, ArI, to some iodine(III) intermediates, which in the subsequent reactions gave the desired final products, viz. $\mathrm{ArI}(\mathrm{OAc})_{2}$ (Scheme 2) or $\mathrm{ArIO}_{2}$ (Scheme 3) in good yields. As previously seen [16], in our present work the successful use of sodium periodate as the oxidant also resulted in easy, safe, and effective preparations of twelve $\operatorname{ArI}(\mathrm{OAc})_{2}$ (Table 1) and fourteen $\mathrm{ArIO}_{2}$ (Table 2) from the respective ArI. The oxidative reactions of ArI proceeded smoothly under the conditions given in Experimental, and this positively extends the organic chemistry of polyvalent iodine compounds. Our novel method for preparing $\operatorname{ArI}(\mathrm{OAc})_{2}$ from iodotoluenes and iodoanisoles nicely complements our former method [8]. Also, our novel method for preparing $\mathrm{ArIO}_{2}$ from ArI seems to be interesting, because taking both into account the safety aspects as well as good yields and satisfactory purities (98-99\%) of the crude iodyl compounds obtained by us, this may compete in full with the "classic" results attained formerly by the Indian chemists [11] and their followers (see references in Ref. 14). Our present paper also extends, very interestingly, the known [16] oxidative applicability of $\mathrm{NaIO}_{4}$ in organic synthesis.

\section{Note}

Our preliminary results were presented at the 3rd Symposium on Iodine Utilization, Chiba (Japan), November 24-25, 2000 [18]. They are also related in our latest review: "Organic Iodine (I, III, and V) Chemistry: 10 Years of Development at the Medical University of Warsaw, Poland" [19].

\section{Experimental}

\section{General}

The starting commercial iodoarenes, ArI, were freshly purified prior to use. ${ }^{1} \mathrm{H}-\mathrm{NMR}$ solution spectra of pure (diacetoxyiodo)arenes (Table 1) were taken with a Tesla (100 MHz) spectrometer, while solid IR spectra of iodylarenes (Table 2) were taken with a Perkin-Elmer spectrophotometer. Microanalyses were carried out at the Institute of Organic Chemistry, the Polish Academy of Sciences, Warsaw.

\section{(Diacetoxyiodo)arenes: General Procedure}

$\mathrm{NaIO}_{4}(2.20 \mathrm{~g}, 10.3 \mathrm{mmol} ; 3 \%$ excess $)$ and AcONa (1.8 g, $\left.22 \mathrm{mmol}\right)$ were suspended in a stirred mixture of glacial $\mathrm{AcOH}(15 \mathrm{~mL})$ with $\mathrm{Ac}_{2} \mathrm{O}(1.5 \mathrm{~mL})$. An appropriate iodoarene $(10 \mathrm{mmol})$ was 
added, and the mixture was stirred and boiled under a reflux condenser for $2 \mathrm{~h}$, cooled to r. t., and next poured into water $(50 \mathrm{~mL})$. The precipitates (unless otherwise stated below) were collected by filtration, washed thoroughly with $10 \%$ aq. $\mathrm{AcOH}(2 \times 10 \mathrm{~mL})$ [17] to remove possibly all soluble impurities, and air-dried in the dark. The yellowish crude products were recrystallized from EtOAc/ $\mathrm{Ac}_{2} \mathrm{O}(9: 1, \mathrm{v} / \mathrm{v})$. After short boiling, the yellowish solutions faded (cf. Ref. 8) and, after cooling, hexane was added in excess (Table 1) with stirring. After $30 \mathrm{~min}$, the crystals were collected by filtration, washed with hexane and air-dried in the dark. See Table 1 for more details.

Table 1. Preparative details, melting points (uncorrected) and ${ }^{1} \mathrm{H}-\mathrm{NMR}$ solution spectra of the purified (diacetoxyiodo)arenes obtained. ${ }^{\text {a) }}$

\begin{tabular}{|c|c|c|c|c|c|}
\hline $\mathbf{R}^{\mathbf{b})}$ & $\begin{array}{c}\text { Crystallization } \\
\text { solvent }^{\mathrm{c})}\end{array}$ & $\begin{array}{l}\text { Yield } \\
(\%)\end{array}$ & $\begin{array}{l}\mathrm{Mp} \\
\left({ }^{\mathbf{o}} \mathrm{C}\right) \\
\end{array}$ & $\begin{array}{l}\text { Lit, mp } \\
\left({ }^{\circ} \mathrm{C}\right)\end{array}$ & $\begin{array}{c}{ }^{1} \mathrm{H}-\mathrm{NMR}\left(\mathrm{CDCl}_{3} / \mathrm{TMS}\right) \\
\delta(\mathrm{ppm}) \\
\end{array}$ \\
\hline $\mathrm{H}$ & $\mathrm{B}$ & 73 & $161-63$ & $161.1-162.2[20]$ & $2.01\left(\mathrm{~s}, 6 \mathrm{H}, \mathrm{MeCO}_{2}\right), 7.45-8.13(\mathrm{~m}, 5 \mathrm{H}, \mathrm{ArH})$ \\
\hline $4-\mathrm{F}$ & A & 71 & $180-82$ & $177.0-179.8[20]$ & $2.01\left(\mathrm{~s}, 6 \mathrm{H}, \mathrm{MeCO}_{2}\right), 7.12-8.14$ (sym. m, 4H, ArH). \\
\hline $2-\mathrm{Cl}$ & $\mathrm{B}$ & 45 & $140-42$ & $140-142[8]$ & $2.00\left(\mathrm{~s}, 6 \mathrm{H}, \mathrm{MeCO}_{2}\right), 7.32-8.27(\mathrm{~m}, 4 \mathrm{H}, \mathrm{ArH})$ \\
\hline $3-\mathrm{Cl}$ & B & 68 & $156-58$ & $153.1-154.7[20]$ & $2.02\left(\mathrm{~s}, 6 \mathrm{H}, \mathrm{MeCO}_{2}\right), 7.41-8.10(\mathrm{~m}, 4 \mathrm{H}, \mathrm{ArH})$. \\
\hline $4-\mathrm{Cl}$ & $\mathrm{C}$ & 69 & $114-16$ & $109.8-113.2[20]$ & $2.01\left(\mathrm{~s}, 6 \mathrm{H}, \mathrm{MeCO}_{2}\right), 7.43-8.06$ (sym. m, 4H, ArH). \\
\hline $4-\mathrm{Br}$ & $\mathrm{C}$ & 50 & $120-22$ & $120-122[8]$ & $2.01\left(\mathrm{~s}, 6 \mathrm{H}, \mathrm{MeCO}_{2}\right), 7.59-7.99$ (sym. m, 4H, ArH). \\
\hline 2-Me & $\mathrm{C}$ & 64 & $140-42$ & $140-142[21]$ & $\begin{array}{l}2.00\left(\mathrm{~s}, 6 \mathrm{H}, \mathrm{MeCO}_{2}\right), 2,75(\mathrm{~s}, 3 \mathrm{H}, \mathrm{Me}), 7.45-8.20(\mathrm{~m}, \\
4 \mathrm{H}, \mathrm{ArH}) .\end{array}$ \\
\hline 3-Me & B & 71 & $153-55$ & $154[22]$ & $\begin{array}{l}2.02\left(\mathrm{~s}, 6 \mathrm{H}, \mathrm{MeCO}_{2}\right), 2.44(\mathrm{~s}, 3 \mathrm{H}, \mathrm{Me}), 7.35-8.00(\mathrm{~m}, \\
\text { 4H, ArH). }\end{array}$ \\
\hline 4-Me & B & 77 & $108-10$ & $106-110[20]$ & $\begin{array}{l}2.00\left(\mathrm{~s}, 6 \mathrm{H}, \mathrm{MeCO}_{2}\right), 2.47(\mathrm{~s}, 3 \mathrm{H}, \mathrm{Me}), 7.25-8.03 \text { (sym. } \\
\text { m, } 4 \mathrm{H}, \mathrm{ArH}) .\end{array}$ \\
\hline 2-OMe & $\mathrm{B}$ & 65 & $147-49$ & $146.9-150.1[20]$ & $\begin{array}{l}1.99\left(\mathrm{~s}, 6 \mathrm{H}, \mathrm{MeCO}_{2}\right), 4.00(\mathrm{~s}, 3 \mathrm{H}, \mathrm{OMe}), 6.92-8.18(\mathrm{~m}, \\
4 \mathrm{H}, \mathrm{ArH}) .\end{array}$ \\
\hline 3-OMe & $\mathrm{C}$ & 74 & $133-35$ & not reported & $\begin{array}{l}2.02\left(\mathrm{~s}, 6 \mathrm{H}, \mathrm{MeCO}_{2}\right), 3.90(\mathrm{~s}, 3 \mathrm{H}, \mathrm{OMe}), 7.03-7.70(\mathrm{~m}, \\
4 \mathrm{H}, \mathrm{ArH})\end{array}$ \\
\hline 4-OMe & $\mathrm{D}$ & 73 & $88-90$ & $92.4-96.0[20]$ & $\begin{array}{l}2.00\left(\mathrm{~s}, 6 \mathrm{H}, \mathrm{MeCO}_{2}\right), 3.87(\mathrm{~s}, 3 \mathrm{H}, \mathrm{OMe}), 6.90-8.07 \\
\text { (sym. m, 4H, ArH). }\end{array}$ \\
\hline
\end{tabular}

a) Satisfactory microanalyses ( $\% \mathrm{I} \pm 0.3)$ obtained for all pure products. b) See Scheme 2 for the explanation. c) Solvent A: EtOAc/hexane (1:1); Solvent B: EtOAc/hexane (1:2); Solvent C: EtOAc/hexane (1:3); Solvent D: EtOAc/hexane (1:4); the EtOAc used was admixtured with $\mathrm{Ac}_{2} \mathrm{O}(9: 1, \mathrm{v} / \mathrm{v})$. See Experimental for details.

Note. The oily or semisolid crude 4- $\mathrm{ClC}_{6} \mathrm{H}_{4} \mathrm{I}(\mathrm{OAc})_{2}$, 4- $\mathrm{MeC}_{6} \mathrm{H}_{4} \mathrm{I}(\mathrm{OAc})_{2}$, and 4- $\mathrm{MeOC}_{6} \mathrm{H}_{4} \mathrm{I}(\mathrm{OAc})_{2}$ were extracted with $\mathrm{CH}_{2} \mathrm{Cl}_{2}(3 \times 10 \mathrm{~mL})$. The collected extracts were dried $\left(\mathrm{Na}_{2} \mathrm{SO}_{4}\right)$, the solvent was distilled off under reduced presure, and the residues were triturated with hexane $(15 \mathrm{~mL})$ until they solidified. The solids were collected by filtration, washed with hexane, and air-dried in the dark. Next, they were recrystallized as above to give the pure products (Table 1). 


\section{Iodylarenes: General Procedure}

$\mathrm{NaIO}_{4}$ (4.70 g, $22 \mathrm{mmol} ; 10 \%$ excess) was suspended in water $(20 \mathrm{~mL})$. An appropriate iodoarene (10 mmol) was added with stirring; for ArI which are steam-volatile, 0.1-0.3 mL of toluene was also added to prevent their accumulation in the reflux condenser. The mixtures were vigorously stirred and refluxed for 8-16 h (Table 2). Next, ice water $(50 \mathrm{~mL})$ was added with stirring, and the temperature was lowered to r.t. The crude products were collected by filtration, washed with cold water $(2 \times 10$ $\mathrm{mL})$ and $\mathrm{CHCl}_{3}$ or $\mathrm{Me}_{2} \mathrm{CO}(3 \times 10 \mathrm{~mL})$ to remove the unreacted $\mathrm{ArI}$ and $\mathrm{PhMe}$, and air-dried in the dark; the crude yields are given in Table 2. Small crude samples were recrystallized from boiling water to give the analytically pure products. For 2- and 4-iodobenzoic acids, their sodium salts (10 mmol) should be used instead of the parent acids to obtain the respective iodylbenzoic acids (see below).

Table 2. Preparative details, melting points (uncorrected) and IR solid spectra of the purified iodylarenes obtained. ${ }^{\text {a) }}$

\begin{tabular}{|c|c|c|c|c|c|}
\hline $\mathbf{R}^{\mathbf{b})}$ & $\begin{array}{c}\text { Time } \\
\text { (h) }\end{array}$ & $\begin{array}{c}\text { Crude } \\
\text { yield } \\
(\%)\end{array}$ & $\begin{array}{l}\text { Mp } \\
\left({ }^{0} \mathrm{C}\right)\end{array}$ & $\begin{array}{l}\text { Lit. } \mathrm{mp} \\
\left({ }^{\circ} \mathrm{C}\right)\end{array}$ & $\begin{array}{c}\text { IR spectra }(\mathrm{KBr}) \\
\left(\mathrm{cm}^{-1}\right)\end{array}$ \\
\hline $\mathrm{H}$ & 8 & 86 & 236 expl. & 235 expl. [23] & $771,757,745(?), 731,713\left(\mathrm{IO}_{2}\right)$ \\
\hline 4-OMe & 8 & 85 & 224 expl. & 225 dec. $[24]$ & 2838 (sym. C-H), 1243 (C-O), 767, 740 (?), $713\left(\mathrm{IO}_{2}\right)$. \\
\hline 2-Me & 8 & 61 & 209 expl. & $208[25]$ & $767,750,740(?), 714\left(\mathrm{IO}_{2}\right)$. \\
\hline 3-Me & 8 & 77 & 219 expl. & 220 expl. [26] & $775,764,744(?), 722\left(\mathrm{IO}_{2}\right)$. \\
\hline 4-Me & 8 & 80 & 226 expl. & 229 dec. $[27]$ & $766,741(?), 717\left(\mathrm{IO}_{2}\right)$ \\
\hline $4-\mathrm{F}$ & 12 & 91 & 262 expl. & $248[28]$ & $766,742(?), 713\left(\mathrm{IO}_{2}\right)$ \\
\hline $3-\mathrm{Cl}$ & 12 & 75 & 232 expl. & 233 expl. [29] & 781, 764, $743(?), 711\left(\mathrm{IO}_{2}\right)$ \\
\hline $4-\mathrm{Cl}$ & 12 & 80 & 248 expl. & 243 expl. [29] & $771,743(?), 725,715\left(\mathrm{IO}_{2}\right)$. \\
\hline $4-\mathrm{Br}$ & 16 & 73 & 241 expl. & 240 expl. [30] & $771,744(?), 719\left(\mathrm{IO}_{2}\right)$ \\
\hline $3-\mathrm{NO}_{2}$ & 8 & 85 & 233 expl. & 214 dec. [31] & 1532 (asym. $\left.\mathrm{NO}_{2}\right), 1349$ (sym. $\left.\mathrm{NO}_{2}\right), 763,741(?), 727,707\left(\mathrm{IO}_{2}\right)$. \\
\hline $4-\mathrm{NO}_{2}$ & 16 & 58 & 230 expl. & 215 dec. [31] & 1530 (asym. $\left.\mathrm{NO}_{2}\right), 1351$ (sym. $\left.\mathrm{NO}_{2}\right), 771,747$ (?), 734, $721\left(\mathrm{IO}_{2}\right)$. \\
\hline 2-COOH & 12 & $76^{\mathrm{c})}$ & 260 dec. & 234 dec. $[25]$ & $1608(\mathrm{C}=\mathrm{O}), 741(?)^{\mathrm{d})}$ \\
\hline $2-\mathrm{COONa}^{\mathrm{e}}$ & 12 & $71^{\mathrm{f})}$ & 231 expl. & 233 dec. [18] & $1634(\mathrm{C}=\mathrm{O}), 778(\mathrm{I}-\mathrm{O}), 746(?)$. \\
\hline $3-\mathrm{COOH}$ & 12 & $89^{\mathrm{g})}$ & $250 \mathrm{dec}$. & 243 expl. [32] & $1686(\mathrm{C}=\mathrm{O}), 760,745(?), 734,715$. \\
\hline $4-\mathrm{COONa}{ }^{\mathrm{e}}$ & 16 & $88^{\mathrm{h})}$ & 240 expl. & 245 expl. [33] & $1683(\mathrm{C}=\mathrm{O}), 771,752,741(?), 718$. \\
\hline
\end{tabular}

a) Satisfactory microanalyses ( $\% \mathrm{I} \pm 0.2)$ obtained for all pure products. b) See Scheme 3 for the explanation. c) 1-Hydroxy-1,2-benziodoxol-3(1 H)-one, $\mathrm{C}_{7} \mathrm{H}_{5} \mathrm{IO}_{3}$, admixtured with ca. $5 \%$ of its 1-oxide derivative. For the pure product: found: $\mathrm{C}, 31.9$; H, 1.9; I, 48.3; calcd: C, 31.85; H, 1.91; I, 48.06. It readily oxidized KI in a saturated aq. solution of sodium borate [15]. d) In our opinion, a band located at $740-747 \mathrm{~cm}^{-1}$ is due to a Ar-H (def.) vibration. e) Sodium salts prepared in situ were used as the starting substrates; for more details see Experimental. f) 1-Hydroxy-1,2-benziodoxol-3(1H)-one 1-oxide, $\mathrm{C}_{7} \mathrm{H}_{5} \mathrm{IO}_{4}$. For the pure product: found: $\mathrm{C}, 30.1$; H, 1.8; I, 45.3; calcd: C, 30.03; H, 1.80; I, 45.32. g) For the pure 3-iodylbenzoic acid, $\mathrm{C}_{7} \mathrm{H}_{5} \mathrm{IO}_{4}$ : found: C, 29.9; 
H, 1.7; I, 45.4; calcd: C, 30.03; H, 1.80; I, 45.32. h) For the pure 4-iodylbenzoic acid, $\mathrm{C}_{7} \mathrm{H}_{5} \mathrm{IO}_{4}$ : found: $\mathrm{C}, 30.0$; H, 1.8; I, 45.3; calcd: C, 30.03; H, 1.80; I, 45.32.

Preparation of "2-Iodylbenzoic acid”, i. e. 1-Hydroxy-1,2-benziodoxol-3(1H)-one-1-oxide:

2-Iodobenzoic acid (2.48 g, $10 \mathrm{mmol})$ was slowly added portionwise, with stirring, to a solution of $\mathrm{NaHCO}_{3}(0.86 \mathrm{~g}, 10.2 \mathrm{mmol})$ in water $(20 \mathrm{~mL})$ (foaming!). Next, $\mathrm{NaIO}_{4}(4.70 \mathrm{~g}, 22 \mathrm{mmol} ; 10 \%$ excess) was added, and the mixture was stirred and refluxed for $12 \mathrm{~h}$. After cooling to r.t., this was poured, with stirring, into water $(50 \mathrm{~mL})$ acidified with conc. $(98 \%) \mathrm{H}_{2} \mathrm{SO}_{4}(0.6 \mathrm{~mL})$. The strongly acidic mixture (Congo Red) was left at r.t. for $30 \mathrm{~min}$. The white precipitate was collected by filtration, washed thoroughly with cold water $(2 \times 10 \mathrm{~mL})$ next with $\mathrm{Me}_{2} \mathrm{CO}$ to remove the unreacted 2$\mathrm{HOOCC}_{6} \mathrm{H}_{4} \mathrm{I}$, and air-dried in the dark to give $71 \%$ crude yield. Small crude sample was recrystallized from boiling water to give the analytically pure product. The same procedure is appropriate for the preparation of 4-iodylbenzoic acid, obtained from $4-\mathrm{IC}_{6} \mathrm{H}_{4} \mathrm{COONa}(10 \mathrm{mmol})$ in $88 \%$ crude yield. These two crude products did not oxidize KI in a saturated sodium borate solution, a reaction which differentiates iodosyl compounds from iodyl compounds [15].

\section{References and Notes}

1. Willgerodt, C. Die organischen Verbindungen mit mehrwertigem Jod; Enke Verlag: Stuttgart, 1914.

2. Reviews on (diacyloxyiodo)arenes: a) Varvoglis, A. Chem. Soc. Rev. 1981, 10, 377; b) Merkushev, E.B. Usp. Khim. 1987, 56, 1444; pp 1453-1467 [Chem. Abstr. 1988, 108, 204265]; c) Kirschning, A. J. Prakt. Chem./Chem.-Ztg. 1998, 340, 184; d) Pohnert, G. J. Prakt. Chem. 2000, 342, 731; e) Tohma, H. Yakugaku Zasshi 2000, 120, 620 [Chem. Abstr. 2000, 133, 222460]; f) Arisawa, M.; Toma, H.; Kita, Y. Yakugaku Zasshi 2000, 120, 1061 [Chem. Abstr. 2001, 134, 29586].

3. Varvoglis, A. The Organic Chemistry of Polycoordinated Iodine; VCH: Weinheim, 1992.

4. Stang, P.J.; Zhdankin, V.V. Chem. Rev. 1996, 96, 1123.

5. Varvoglis, A. Hypervalent Iodine in Organic Synthesis; Academic Press: San Diego, 1997.

6. Recent reviews on organohypervalent iodine compounds and their applications in organic synthesis: a) Kitamura, T.; Fujiwara, Y. Org. Prep. Proced. Int. 1997, 29, 409; b) Varvoglis, A. Tetrahedron 1997, 53, 1179; c) Muraki, T.; Togo, H.; Yokoyama, M. Rev. Heteroatom Chem. 1997, 17, 213; d) Kitamura, T. Kagaku (Kyoto) 1997, 52, 62 [Chem. Abstr. 1997, 127, 121516]; e) Togo, H.; Hoshina, Y.; Nogami, G.; Yokoyama, M. Yuki Gosei Kagaku Kyokaishi 1997, 55, 90 [Chem. Abstr. 1997, 126, 156952]; f) Moriarty, R.M.; Prakash, O. Adv. Heterocycl. Chem. 1998, 69, 1; g) Kirschning, A. Eur. J. Org. Chem. 1998, 2267; h) Zhdankin, V.V.; Stang, P.J. Tetrahedron 1998, 54, 10927; i) Varvoglis, A.; Spyroudis, S. Synlett 1998, 221; j) Ochiai, M. Kikan Kagaku Sosetsu 1998, 34, 181 [Chem. Abstr. 1998, 129, 216196]; k) Hypervalent Organic Compounds (book in Japanese); Anon.; Gakkai Shuppan Center: Tokyo, 1998 [Chem. Abstr. 1999, 131, 18605]; 1) Ochiai, M. Farumashia 1999, 35, 140 [Chem. Abstr. 1999, 130, 153211]; m) Muraki, T.; Togo, H.; Yokoyama, M. J. Org. Chem. 1999, 64, 2883; n) Kita, Y.; Egi, M.; Takada, 
T.; Toma, H. Synthesis 1999, 885; o) Wirth, T.; Hirt, V.H. Synthesis 1999, 1271; p) Muller, U. Trends Photochem. Photobiol. 1999, 5, 117; q) Chemistry of Hypervalent Compounds; Akiba, K., Ed.; Wiley-VCH: New York, 1999; Chapter 11 and 12; r) Grushin, V.V. Chem. Soc. Rev. 2000, 29, 315; s) Ochiai, M.; Kitagawa, Y. Yuki Gosei Kagaku Kyokaishi 2000, 58, 1048 [Chem. Abstr. 2000, 133, 362660]; t) Tohma, H. Yakugaku Zasshi 2000, 120, 620 [Chem. Abstr. 2000, 133, 222460]; u) Mamaeva, E.A.; Bakibaev, A.A. Izv. Vyssh. Uchebn. Zaved. Khim. Khim. Tekhnol. 2000, 43, 53 [Chem. Abstr. 2000, 133, 266754]; v) Arisawa, M.; Toma, H.; Kita, Y. Yakugaku Zasshi 2000, 120, 1061; Chem. Abstr. 2001, 134, 29586.

7. McKillop, A.; Kemp, D. Tetrahedron 1989, 45, 3299.

8. Kazmierczak, P.; Skulski, L. Synthesis 1998, 1721.

9. Chaundhari, S.S. Synlett 2000, 278.

10. Sharefkin, J.G.; Saltzman, H. Org. Synth. 1963, 43, 65.

11. Banarjee, A.; Banarjee, G.C.; Bhattacharia, S.; Banarjee, S.; Sammadar, H. J. Indian Chem. Soc. 1981, 58, 605 .

12. Lucas, H J.; Kennedy, E.R. Org. Synth. 1942, 22, 72.

13. Bayraktaroglou, T.O.; Gooding, M.A.; Khatib, S.F.; Lee, M.; Kourouma, M.; Landot, R.G. J. Org. Chem. 1993, 58, 1264.

14. Frigerino, M.; Santagostino, M.; Sputore, S. J. Org. Chem. 1999, 64, 4537.

15. a) Lucas, H.J.; Kennedy, E.R.; Formo, M.W. Org. Synth. 1942, 22, 70; b) Fieser, L.F.; Fieser, M. Reagents for Organic Synthesis; Wiley-Interscience: New York, 1967; Vol. 1, p 511.

16. Quite recently, we successfully applied $\mathrm{NaIO}_{4}$ for the oxidative iodination of both activated and deactivated arenes in some anhydrous $\mathrm{I}_{2} / \mathrm{NaIO}_{4} / \mathrm{AcOH} / \mathrm{Ac}_{2} \mathrm{O} /$ conc. $\mathrm{H}_{2} \mathrm{SO}_{4}$ mixtures; see: Lulinski, P.; Skulski, L. Bull. Chem. Soc. Jpn. 2000, 73, 951. For the application of $\mathrm{NaIO}_{4}$ in organic synthesis see the following reviews: a) Fatiadi, A.J. Synthesis 1974, 229; b) Fatiadi, A.J. In Synthetic Reagents; Pizey, J.S., Ed.; Halsted Press-Wiley: New York, 1981; Vol. 4; c) Fieser, L.F.; Fieser, M. Reagents for Organic Synthesis; Wiley-Interscience: New York, continued since 1967; Vols. 1-20.

17. The crude (diacetoxyiodo)arenes are more soluble in water than in $10 \%$ aq. $\mathrm{AcOH}$, hence washing the crystals with distilled water gave lower yields; cf. Ref. [8].

18. See: FIU (Forum on Iodine Utilization) Report No. 3, 2000, pp 105-106.

19. Skulski, L. Molecules, 2000, 5, 1331, pp. 1354 and 1356-1357. Avail. at URL: http://www.mdpi.org/molecules/papers.51201331.pdf

20. Leffler, J.E.; Story, L.J. J. Am. Chem. Soc. 1967, 89, 2333.

21. Karele, B.Ya.; Neiland, O.Ya. Latv. PSR Zinat. Akad. Vestis, Kim. Ser. 1970, 587 [Chem. Abstr. 1971, 74, 42033].

22. Pausacker, K.H. J. Chem. Soc. 1953, 107.

23. Kennedy, R.J.; Stock, A.M. J. Org. Chem. 1960, 25, 1901.

24. Liebrecht, A. German Pat. 161725, 1905; Chem. Zentr. 1905 II, 183.

25. Sharefkin, J.G.; Saltzman, H. Anal. Chem. 1963, 35, 1428.

26. Willgerodt, C.; Umbach, T. Justus Liebigs Ann. Chem. 1903, 327, 269.

27. Datta, R.L.; Choudhury, J.K. J. Am. Chem. Soc. 1916, 38, 1079. 
28. Plesnicar, B. J. Org. Chem. 1975, 40, 22.

29. Willgerodt, C. Ber. Dtsch. Chem. Ges. 1893, 26, 1950.

30. Willgerodt, C. Ber. Dtsch. Chem. Ges. 1893, 26, 361.

31. Yagupolskii, L.M.; Maletina, I.I.; Kondratenko, N. V.; Orda, V.V. Synthesis 1977, 574.

32. Willgerodt, C. Ber. Dtsch. Chem. Ges. 1894, 27, 2330.

33. Bothner-By, A.A.; Medalia, A.I. J. Am. Chem. Soc. 1952, 74, 4402.

Sample Availability: Samples of all pure iodylarenes and (diacetoxyiodo)arenes described in this paper are available through MDPI, however, it must be noted that iodylarenes are generally hazardous compounds, which may explode upon impact, by scratching them with a spatula, etc.

(C) 2001 by MDPI (http://www.mdpi.org). Reproduction is permitted for noncommercial purposes. 